\title{
Um olhar agudo sobre arte e literatura
}

Domicio Proença Filho

O QUADRADO amarelo atrai o leitor ao primeiro contato: é um primoroso objeto gráfico. O prazer plenifica-se no convívio com o texto, que associa, integrados, a sensibilidade do poeta, o rigor da pesquisa, a meticulosidade do historiador, o equilíbrio do memorialista, a percuciência do cultor do ensaio, a fluidez e a elegância do estilo: trata-se de Alberto da Costa e Silva. São aspectos que não surpreendem quem conhece seus Poemas reunidos, as reminiscências de $E s$ pelho do príncipe e de $A$ invenção do desenho, os estudos de $O$ pardal na janela e de Das mãos do oleiro, os oito preciosos livros sobre a África e sua história, destacados $A$ enxada e a lança, $A$ África antes dos portugueses, $A$ manilha e o libambo: a África e a escravidão, de 1500 a 1700.

A singularidade do livro: revela dimensões do crítico de arte e de literatura.

Divide-se o volume em quatro seções: "Formas de olhar", "Modos de ler", "Palavra e canto", "O dia de ontem", escritos iluminadores. Sem preocupações terminológicas ou assunções doutorais. Alberto deixa fluir a navegação de sua sensibilidade, aparentemente livre. Rigorosamente fundada, entretanto, em muitas leituras-fonte e no conhecimento da matéria de que trata. Não se mostra, na feitura - adapto Olavo Bilac -, o esforço do mestre e, natural, o efeito agrada, sem lembrar os andaimes do edifício.

Trata-se de escritos de datas distintas, agora reunidos em livro. Constituem um painel representativo das facetas múltiplas que fazem do autor o intelectual de altíssimos méritos e amplo reconhecimento.

\section{Formas de olhar}

No texto de abertura, considerações sobre duas telas superpostas na memória: uma, inesquecível; outra, senhora de sua preferência. O crítico não se pretende orientador de descodificações: assume a prevalência da subjetividade na emissão dos juízos de valor. De um lado, o figurativo Portrait of a young gentleman, de Antonello da Messina, artista do século XV. De outro, a geometria moderna do quadro de Waldemar da Costa, Apologética do quadrado amarelo, base do título do volume. Comparações. Impactos de beleza pictural. Com os dois quadros ali, reproduzidos, à disposição da leitura pessoal e da fruição do leitor, a estimulálo na descoberta do lugar perfeito para um quadrado amarelo.

Na sequência, o autor de Um rio chamado Atlântico trata de escultura africana. Num comentário livre, revelador de sua intimidade e pleno saber do continente, seu povo, sua história, sua arte. Desvela, inicialmente, aspectos de um saleiro de marfim, quase um pretexto para discorrer sobre as dimensões documentais e monumentais da peça-núcleo e de outras mais, de lugares outros africanos. Invenções prodigiosas, ajuíza, de texturas e contrastes, arte popular da mais alta representatividade. À acuidade do crítico associa-se o saber do historiador, num ensaio altamente esclarecedor sobre a significação cultural da manifestação artística do povo de África. Descreve, minucializa, historia, compara, ilustra. O leitor visualiza as peças, acompanha o percurso que as conduz à avalização dos museus da Europa. A 
palavra do crítico ajuda a penetrar mais agudamente as significações estéticas e históricas abrigadas na arte dos barros e dos bronzes de África:

O que fascinava Vlaminck, Darain, Matisse, Kirchner, Picasso, Braque, Julien Gris, Brancusi, Lipchtiz, Modigliani e tantos outros artistas, no início do século XX, era a construção mental subjacente à maioria das esculturas africanas, o geometrismo que regia as suas formas, a invenção levada a extremos, e a diversidade de cânones estéticos que podia coexistir no espaço reduzido de uma só aldeia. (p.23)

Já se escreveu mais de uma vez que a descoberta da arte negra teve um impacto sobre a arte europeia semelhante ao da revelação da cultura grega na antemanhã do Renascimento. (p.23)

Trocas. Mobilizadoras de algum ideal e seguramente de estímulo.

Alberto aproveita muito de sua vivência de diplomata nas terras de África. Vale-se do que viu, do que viveu e conviveu. Associa tudo isso à sua erudição.

Num breve texto intervalar muda o rumo de sua prosa e parte de apreciações sobre dois filmes, que envolvem amor e bonecas, para comentar, nuclearmente, o livro Las hortensias, do uruguaio Felisberto Hernández.

Volta à matéria africana, em considerações sobre os Saô. Ressalta a história desse povo e o destaque das muralhas que edificaram, cujas cicatrizes permanecem "ao longo dos rios Logone e Chari”. Restos de cidades. E somos levados a pensar com ele que "ficam, durante as inundações, acima das águas e ainda conservam traços das muralhas que as cercavam, lembranças de nações cujos reis, ao ascenderem ao trono, amorosamente de- capitavam as próprias mães e sangravam um touro" (p.54).

Ficamos sabendo, entre outras informações, que os Saô também trabalhavam metais e que "talvez só raramente uma escultura africana seja um retrato [...] mas muitas vezes transcreve um semblante em que toda a coletividade se reconhece, a face eterna do homem da tribo, independentemente de estar vivo ou morto, acordado ou no sono, feliz ou dolorido" (p.59).

O ensaísta deixa claramente fluir a sua emoção diante das manifestações da arte e dedica o próximo texto a Abelardo Rodrigues e seu acervo. Diz-nos do devotamento do colecionador ao mundo visível e às criações dos seus semelhantes, entre elas a excepcional coletânea de arte sacra e as manifestações indígenas acolhidas com entusiasmo. Informa-nos sobre a biografia e o dinamismo da ação do artista na divulgação da pintura brasileira. Homenagem e reconhecimento. Aproximações.

Retorna à apreciação do popular em dois textos. No primeiro, dedicado ao pintor Lula Cardoso Aires e a seus quadros feitos de pinturas de bonecos de barro, destaca a captação da essencialidade das cenas corriqueiras do Nordeste, as reminiscências nordestinas que lhe traz a visão de sua obra. Dedica o segundo às formas de olhar de Mestre Dezinho de Valença do Piauí, artista do povo, traduzidas nas imagens que esculpiu e que adornam, em Teresina, a Igreja de Nossa Senhora de Lourdes, que com ele visitamos em seu texto, em companhia de José Guilherme Merquior. Na base do longo ensaio, a descrição e a comparação com obras europeias, frequentadoras de museus e da melhor crítica avalizadora. Associa essa arte escultural às produções da Alta Idade Média, com a convicção 
declarada de que "toda arte, e sobretudo a grande arte, nasce do diálogo com o passado". E explicita, a partir de uma das obras do Mestre:

São distintos o vocabulário e a urdidura das metáforas entre o artista dito culto e o chamado artista popular. Mas, ao voltar-me para as mãos de Bernadette que recebe a visita da Virgem de Lourdes, na Vermelha, as diferenças no tempo, no material, na técnica e na concepção da vida e da arte não impedem que a memória de meus olhos as irmane, em sua tensão expressiva, às que a Dama com Flores de Verrocchio (no Bargello, em Florença) encosta ao peito. (p.101)

Curiosamente, a apreciação crítica flui associada à narrativa da visita.

$\mathrm{Na}$ mesma linha de pensamento, seu olhar atento volta-se para uma coleção de imagens de santos e objetos de prata que João Marino traz de São Paulo para exibir em Lisboa, na Fundação Calouste Gulbenkian, também centrada na arte popular de santeiros e artesãos, notadamente "barristas e talhadores que saíram de seus vilarejos escondidos, para atravessar o Atlântico". A partir delas, novas considerações sobre o percurso dessa arte em terras coloniais do Brasil.

Conclui esse primeiro segmento com três breves textos. $\mathrm{O}$ primeiro, sobre o diálogo pictural de Carlos Bracher com Van Gogh, deliberadamente assumido, diálogo-homenagem, que considera além da mera repetição ou pastiche, mas continuação, centrada "no desejo vangoghiano de desenhar com a própria cor". O segundo, nuclearizado nas tapeçarias de Concessa Colaço. O último da série, uma página sobre o traço de Carybé, testemunho e documento da gente e dos mistérios da Bahia.

\section{Modos de ler}

O texto de abertura surpreende pela mudança de estilo. Agora é a frase curta, o corte na estrutura sintática tradicional. É a reflexão a predominar sobre a descrição. Mas ainda é a visão armada. Lançada, iluminadora, sobre retratos, fotografias. O autor permite-se filigranar o seu estilo.

Retorna a escritura anterior nas apreciações seguintes do crítico de literatura.

Perpassa criticamente a obra de Guimarães Rosa, num texto datado de 1961. Entende, com acerto, que é autor de estórias para serem lidas como se ouvia: frase a frase. Rastreia o percurso da ficção brasileira centrada na realidade sertaneja e na aproximação com a fala do povo. Ressalta a dimensão simultaneamente brasileira e universal do autor de Corpo de baile. Mobiliza, com a radicalidade do seu juízo de valor, a reflexão dos colegas de ofício: "Sagarana rompe, no entanto, com os processos ingênuos que crivam de infelicidade a maior parcela da ficção telúrica brasileira - na qual só existia realmente um grande livro: Fogo morto" (p.129).

O próximo comentário, de 1999, envolve Bolor, de Augusto Abelaira, na sua edição brasileira. Considera-o "um grande escritor", de linhagem machadiana. De palavras afiadas, "manejadas como parte do enredo, expresivamente perfeitas, e claras, e precisas, e agudas, e diretas". Uma resenha nuclearizada no estilo e na comparação de que a adjetivação exemplificada dá a medida.

O objeto do texto seguinte, escrito em 2001, é O Ateneu, de Raul Pompéia. Alberto compara a técnica do romancista à arte da pintura. E lê romance além da sátira e da écriture artistique a que a 
crítica costuma associá-lo. Valoriza o que chama de "o nervosismo de uma linguagem que nasce como verdade na boca e na mão de um hipersensível que carrega o início de uma adolescência como um peso doloroso no coração machucado e faz de sua história a verdadeira carta de quem se adivinha suicida" (p.138).

Entende, e desde a primeira leitura que, na juventude, fez do romance, que "o grande tema desse livro é um menino com medo. Com medo da orfandade da vida". Centraliza, portanto, o juízo na construção do personagem. Considera o livro "quase perfeito". E, fiel à sua pena crítica, compara, assinalando diferenças, para acentuar singularidades. Com o menino de Casimiro de Abreu, com suas saudades da aurora de sua vida, com a sofrida criança preservada por Humberto de Campos nas suas Memórias, com Infância, de Graciliano Ramos, O nariz do morto, de Antônio Carlos Villaça, Chove sobre a minha infância, de Miguel Sanchez Neto, e ainda com Menino de engenho, de José Lins do Rego, Segredos de infância, de Augusto Meyer, O menino e o palacete, de Thiers Martins Moreira, Histórias da minha infância, de Gilberto Amado, os poemas de Menino antigo, de Carlos Drummond de Andrade, Baú de ossos e Balão cativo, de Pedro Nava, Prosas, de José Paulo Paes. Comparar: mais um procedimento recorrente na sua leitura crítica. Ao leitor deixa a abertura para as suas próprias conclusões e ampliações.

A resenha seguinte, do mesmo ano, percorre a obra do amigo Herberto Sales, ao ensejo da data em que completaria, vivo fosse, 84 anos de idade: 21 de setembro de 2001. Comenta a linguagem de seus romances, o seu relacionamento com sua obra. Segue-se outra resenha, agora sobre o livro de Maria
Lúcia Palhares-Burke, uma biografia de Gilberto Freyre, que considera "muitíssimo bem escrito".

E retorna à Africa, tema de sua especial predileção, e ao aprofundamento. Para situá-la em sua relação com a literatura brasileira. Retoma Castro Alves e sua África literária, que considera longe do real, e o documentado Coelho Neto, do romance Rei negro. Aponta vaguedade e referências indiretas dos poemas negros de Jorge de Lima, centrado mais na "África como fonte de palavras. De palavras quimbundas, umbundas, quicongas, fons e iorubanas, que o poeta usou com grande mestria, com uma percepção de seus valores sonoros e plásticos", uma África, para o crítico, vocabular. Louva Luanda, Beira, Babia, de Adonias Filho, como belo romance, mas ressalta que a África nele mostrada "são franjas portuguesas da África colonizada, com os africanos como figurantes menores, quase estrangeiros". Afirma que é com Antônio Olinto que o continente negro entra de verdade na nossa literatura, com A casa da água, O rei de Keto e Trono de vidro. Destaca ainda Ganga-Zumba, de João Felício dos Santos, Tróia negra, de Jorge Landmann, e $O$ trono da rainha Jinga, de Alberto Mussa. Em sua maioria, trata-se de textos que situam o negro numa visão distanciada. Um contraponto interessante seria a comparação com negros e descendentes de negros que escreveram poemas e ficção compromissados com a etnia, como sujeitos do seu próprio discurso. O ensaio do crítico abre espaço para esta perspectiva.

A África presentifica-se ainda, embora indiretamente, no escrito de 2005 sobre o fotógrafo e estudioso da cultura africana "Pierre Verger, de parisiense a afro-brasileiro". 


\section{Palavra e canto}

A seção faz-se de estudos críticos, autores e sobre textos.

Em "Fernando Pessoa, grego", Alberto privilegia a intertextualidade.

Um ensaio sobre Augusto Meyer apoia-se em associações. Poema-puxapoema. Poeta-puxa-poeta. O crítico dialoga, de início, com antigo texto seu e com um texto de seu pai Da Costa e Silva, e segue costurando relações, influências, intertextos. Ao fundo, sua erudição, a riqueza de sua bagagem de leituras. Ao longo da análise empreendida, ainda uma vez a comparação. Sem preocupação com modelizações, teorias apriorísticas. Reflexões de leitor excepcionalmente municiado. Em destaque, o gauchismo presente na obra do poeta. Na paisagem e no vocabulário. Os adjetivos do crítico revelam o seu entusiasmo pelo autor de Poemas de Bilu.

"Morte no avião", o poema de Carlos Drummond de Andrade, ganha leitura original, nuclearizada no humor drummondiano. Lateralmente, ainda comparações. Com Manuel Bandeira, com Augusto Meyer.

"Um sonho como pretexto" reúne poemas de José Paulo Moreira da Fonseca, Ferreira Gullar, Fernando Pessoa e seus heterônimos, em reflexões em torno de grafismo.

Um estudo sobre Augusto dos Anjos apoia-se na categoria estilo epocal. E, sempre, a literatura comparada, a leitura inntertextual. Agora destacados Camões, Antero de Quental, Bocage, Cesário Verde, Bilac. Semelhanças e dessemelhanças. Assinalada, a construção anteriana e camoniana dos sonetos do poeta, a presença do trágico e da visão pessimista. Na diferença, o evolucionismo assumido e a aspiração nirvânica que

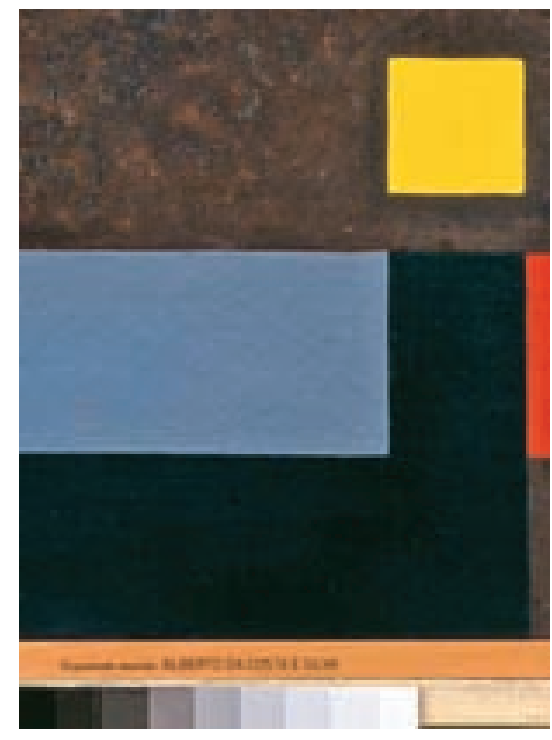

COSTA E SILVA, Alberto da. O quadrado amarelo. São Paulo: Imprensa Oficial do Estado de São Paulo, 2009. 248p. 73il.

se depreende da poesia do brasileiro, o vocabulário buscado nas ciências biológicas e no monismo de Haeckel, no evolucionismo de Spencer. Destacada, a sua atualidade. No processo literário brasileiro, o crítico aponta com originalidade, e fundamenta a sua tese, o diálogo com Bilac, ressaltado o dilaceramento da poesia do primeiro.

Marly de Oliveira tem a sua poesia analisada na minuciosa resenha que traz seu livro Retrato como ponto de referência nuclear. O crítico situa o volume como uma autorreleitura do itinerário poético que Marly empreende, à semelhança do que fez o crítico espanhol Carlos Bousoño. Mas, assinala, em outra direção: trata-se de um diálogo de versos, os novos relendo os antigos, numa revisão de si mesma, como poeta, como vida. Elogia a limpidez da linguagem, o vocabulário de tradição camoniana, o visualismo das imagens, a tranquilidade 
da sensualidade, "aguçada em sua aspiração mística". Considera-a "senhora do verso" e da "estrofe luminosa, precisa e sempre emocionada". Entende que, no livro em exame, "descreve-se a busca da unidade entre o ser e o fazer, entre a vida e o poema, no correr do tempo". Amplia a percepção do silêncio do texto.

A leitura de $A$ árvore seca, livro de Alexei Bueno, resenhada na sequência, aponta o desencanto, a amargura, a desesperança, que marcam seus poemas. Destaca, como marca dominante na técnica do poeta, o apego às formas fixas e tradicionais, bem medidas e ritmadas.

Outra resenha repassa criticamente a poesia de Oswaldino Marques, a partir da leitura de Usina do sonho. Alberto ajuíza, elogia, descreve, aponta temas dominantes. O leitor que usufrui superpõe-se ao crítico que analisa.

O último objeto dos modos de ler é a Antologia efêmera do "por dentro e por fora português” E. M. de Melo Castro. Livro em que, no juízo do crítico, se conta "a vida de um poeta sanguíneo, exuberante a apaixonado, que marcou com sua pregação, atividade e exemplo meio século de poesia portuguesa", de "um dos porta-estandartes de uma geração que surgiu apertada entre a intolerância salazarista e o sectarismo dos neorrealistas, mas acabou por colocar Portugal em dia com o resto do Ocidente", "um vanguardista tradicionalista, do mesmo modo que é um barroco contido". $\mathrm{Na}$ base da leitura, a dinâmica do processo literário.

\section{O dia de ontem}

A apreciação crítica cede espaço, nesse último bloco, a dois textos-memória: "Lembranças de Lagos", na Nigéria, e "A luz de Lisboa”. Impressões. Descobertas de beleza, de paisagens e de gente. Associações com telas, pinturas. Fecha-se o ciclo: o "quadrado amarelo" encontra as aquarelas de Thomaz Ianelli.

Completa-se o prazer da leitura, clarificadora de espaços de ver além das formas, de ler além do discurso manifesto, de abertura de perspectivas diante das artes plásticas e da literatura. Associamse a visão de mundo do artista, revelada nas obras, e a visão do observador atento, a usufruir-lhes a representatividade como coisas de beleza e de cultura.

Rio de Janeiro, 16 de outubro de 2009

Domício Proença Filho é professor emérito titular de Literatura Brasileira da Universidade Federal Fluminense, aposentado. É autor, entre outras obras, de $A$ linguagem literária; estilos de época na literatura, Pósmodernismo e literatura (estudos críticos). É membro da Academia Brasileira de Letras. @-domicio.proenca@terra.com.br 